УДК 61:378](73)

DOI:

Любов Манюк, кандидат педагогічних наук, старший викладач кафедри латинської та іноземних мов

Наталія Кучумова, кандидат педагогічних наук, доцент кафедри латинської та іноземних мов Львівського національного медичного університету імені Данила Галицького

\title{
МОДЕРНІЗАЦІЯ ПІДГОТОВКИ МАЙБУТНІХ ЛІКАРІВ В УНІВЕРСИТЕТАХ США
}

У статті висвітлено основні результати дослідження досвіду університетів США стосовно модернізації підготовки майбутніх лікарів; описано структуру вищої медичної освіти у США; визначено пріоритетні напрями та перспективи актуалізації освітніх програм і навчальних планів медичних шкіл цієї краӥни. Виявлено, щуо діяльність університетів США спрямована на модернізачію навчального процесу, використання новітніх технологій (електронне навчання, віртуальні пацієнти, телемедииина, мобільні технології, електронні соціальні мережі), впровадження освітніх інновацій у навчальні плани з метою підготовки компетентних лікарів.

Ключові слова: модернізація; майбутній лікар; вища медична освіта; університети США.

Лim. 9.

Lyubov Manyuk, Ph. D.(Pedagogy), Senior Lecturer of the Latin and Foreign Languages Department Nataliya Kuchumova, Ph.D.(Pedagogy), Associate Professor of the Latin and Foreign Languages Department Danylo Halytskiy Lviv National Medical University

\section{MODERN CHANGES IN EDUCATION OF FUTURE PHYSICIANS AT THE UNIVERSITIES OF THE USA}

This paper presents the experience of American universities concerning modern changes in higher medical education; highlights the use of information and communication technologies (ICT) for learning as well as teaching purposes at medical schools. It was revealed that the most significant share of the research in the scope of ICTs usage in medical education is associated with the activity of Harvard, Washington, New York and Michigan schools of medicine. The universities of Ohayo, Illinois, Massachusetts and Wisconsin have also made important contributions into the history of computerization. All US medical schools have the leading positions in ICTs implementation with the core patient-centered approach.

System of the US medical education is characterized by the long-term tradition of innovative development and implementation. The period of medical education is one of the longest in the world. It is directed on training competent and competitive health care specialists. The US government encourages modernization in medical schools. Thus, it aids creation of different institutions and associations aimed at innovative changes in higher medical education, facilitation of teaching and learning adaptation.

The ICTs implemented for medical training include all available sources of electronic learning, mobile learning and telemedicine, virtual patients (mannequins, computerized models of medical encounters), social media. In order to facilitate innovations American medical schools take measures including provision of the access to electronic learning materials and computerized learning tools; integration of real electronic learning tools into the process of study; encouraging university teachers to develop and evaluate virtual reality tools; designing of national protocols for proper implementation and evaluation of virtual reality tools; creation of the councils reviewing of this problem; usage of the computerized programs of medical encounters to optimize the professional clinical and communicative training of the future physicians.

The USA has shown the considerable progress in this direction compared to other countries. The scientists have been continuously investigating the problem of ICT implementation and its prognostic aspects. New technologies are known to improve the learning process on condition that pedagogic technologies and teaching methods are changed.

Keywords: modernization; a future physician; higher medical education; universities of the USA.

П остановка проблеми й аналіз сучасних досліджень. Сучасні соціальні й освітні тенденції провокують специфічні зміни у професійній підготовці фахівців різних галузей, зокрема медичної. Стрімкий розвиток інформаційнокомунікативних технологій спонукає до їх активного залучення у навчальних та професійних цілях. У свою чергу, модернізація освітнього процесу потребує дослідження та аналізу досвіду розвинутих країн, що характеризуються значними досягненнями в цій галузі. Аналіз сучасних наукових праць $[3 ; 4 ; 5$; 8] засвідчує, що прикладом такої країни є США. Тому вивчення досвіду університетів США стосовно модернізації підготовки майбутніх лікарів є метою цієї статті.

Виклад основного матеріалу дослідження. 
Сучасний стан вищої медичної освіти у США $є$ результатом багатовікової історії та культури цієї держави. Сьогодні США має потужну освітню систему та є однією з провідних держав щодо впровадження освітніх інновацій і новітніх технологій умедичній освіті. У США діють понад 150 медичних шкіл, що реалізують тисячі навчальних програм, організовують численні міжнародні проекти і науково-дослідні програми.

Всупереч численним спробам і намірам реформування, загальна структура системи ВМО США стабільно залишається незмінною. За даними Американської Медичної Асоціації (АМА) [2] загальний термін навчання для отримання кваліфікації “лікар” становить від 11 до 16 років. Відповідно до класифікації АМА він складається із трьох послідовних хронологічних етапів, $4-4$ -3-8 , а саме: 1) період домедичного (pre-medical) чотирирічного навчання в коледжі чи університеті та отримання ступеня бакалавра наук, що $\epsilon$ обов’ язковою умовою вступу до медичної школи, 2) чотири роки навчання в медичній школі, після закінчення якої студенти-медики отримують професійну кваліфікацію “доктор медицини” (MD), та 3) від трьох до восьми років резидентури, під час якої відбувається спеціалізація майбутніх лікарів.

У 2013 р. АМА започаткувала проект “Медична школа майбутнього" з метою змін і модернізації навчальних планів ВМНЗ. Завдяки зусиллям тридцяти двох закладів [1] було ініційовано Консорціум пришвидшення змін у медичній освіті та у 2015 р. змінено структуру навчального плану, впроваджено практичну медичну підготовку та роботу з реальними і віртуальними пацієнтами у Центрах симуляції 3 першого року навчання. Окрім цього, об'єднання навчальних закладів працює над упровадженням новітніх технологій із метою підготовки майбутніх лікарів до професійної діяльності.

До провідних закладів - учасників Консорціуму належать медичні школи Гарвардського, Стенфордського, Каліфорнійського (Сан-Франциско), Вашингтонського, НьюЙоркського, Мічиганського, Чиказького університетів, а також медичний коледж Пенсільванського державного університету та медична школа Мейє. Діяльність цих ВМНЗ спрямована на модернізацію навчального процесу, використання новітніх технологій (електронне навчання, віртуальні пацієнти (ВП), телемедицина, мобільні технології), впровадження освітніх інновацій у навчальні плани з метою підготовки компетентних стресостійких, упевнених, допитливих, цілеспрямованих лікарів.
Навчальні програми ВНЗ орієнтовані на формування навичок роботи в команді, проведення лікування з урахуванням потреб та особистості пацієнта (patient-centered care). 3 перших років компонентом навчальних планів $\epsilon$ практична діяльність із пацієнтами: спостереження за реальними хворими і медичноконсультаційна практика зі стандартизованими пацієнтами (СП) та ВП [7; 9].

У медичній школі Нью-Йоркського університету нині змінено методи підготовки майбутніх лікарів до роботи з пацієнтами, впроваджено програми комбінованого навчання на основі відкритих систем і ВП, надано доступ студентам до де-ідентифікованих електронних баз пацієнтів, створено систему е-портфоліо студентів 3 метою відстеження та самостійного регулювання навчальної діяльності за допомогою створеного закладом порталу для самостійного навчання [6].

До інших авторитетних членів Консорціуму належать: школа медицини та медичних наук університету Північної Дакоти, медичний коледж Чиказького університету, медична школа університету Індіани. Науково-педагогічний колектив медичної школи університету Індіани створив навчальну електронну базу даних реальних пацієнтів, використовуючи закодовані дані, завдяки чому неможливо встановити особи пацієнтів, але є змога доступу до інших даних бази під час навчання. У школі медицини i медичних наук університету Північної Дакоти використовуються технології симуляції та обладнання телемедицини 3 метою підготовки студентів-медиків до проведення медичних консультацій та інших професійних дій на відстані [1]. Медичний коледж Чиказького університету активно впроваджує технології мобільного навчання, системи ведення віртуальних щоденників, ведення студентами блогів у ЕСМ під керівництвом експертів медичної галузі.

Медичні університети США досягли великих успіхів у використанні ІКТ. Освітній процес у ВМН3 цієї країни вже давно вийшов за межі традиційного уявлення про аудиторне навчання та стрімко розвивається мережне навчання із залученням Інтернет-технологій і мобільних засобів зв' язку [3; 8, 207]. Вищі навчальні заклади розміщують корисну та потрібну навчальну інформацію на своїх веб-сайтах, платформах для електронного навчання або сторінках у соціальних мережах.

Нині значна кількість досліджень і досягнень у цій галузі належить провідним навчальним закладам, а саме: Гарвардському, Вашингтонському, Нью-Йоркського та Мічиганському університетам, 


\section{МОДЕРНІЗАЦІЯ ПІДГОТОВКИ МАЙБУТНІХ ЛІКАРІВ В УНІВЕРСИТЕТАХ США}

проте наші дослідження засвідчують, що на перших стадіях найбільше в напрямі інформатизації медичної освіти було зроблено в університетах Огайо, Іллінойсу, Массачусетса та Вісконсіна. 3 об'єктивної точки зору варто додати, що всі ВМНЗ США займають високі позиції у галузі новітніх технологій. Широко використовуються віртуальні навчальні середовища (ВНС) і мобільні версії офіційних сайтів, а також безкоштовні мобільні додатки, що забезпечують миттєвий доступ до сайту чи ВНС ВМНЗ за допомогою іконки на дисплеї електронного мобільного пристрою. Ми не виявили жодного університету США, в навчальному арсеналі якого не було б таких засобів. Окрім цього, в медичних школах та коледжах використовуються електронні освітні ресурси та віртуальні пацієнти, а також проводяться спроби використання мобільних технологій та електронних соціальних мереж (ЕСM) у навчальному процесі.

У першій декаді другого тисячоліття електронне навчання було основним напрямом досліджень у галузі медичної освіти [5]. Незважаючи на різноманітність поглядів і трактувань терміну “е-навчання", в його основу всі науковці покладають використання комп'ютерних та інформаційно-комунікаційних технологій з навчальною метою.

Характерним є плюралізм думок стосовно використання ІКТ під час підготовки майбутніх лікарів. Частина дослідників наголошує на необхідності їх застосування як доповнення до наявних методик із метою підвищення якості, швидкості та ефективності навчання. Інші пропонують розглянути нові способи мислення та навчання, яким могли б сприяти новітні технології. Більш ніж десятилітній досвід досліджень і впровадження ІКТ у навчальні процеси ВМНЗ США засвідчує загальний позитивний вплив цих технологій на якість і мотивацію навчання.

Упровадження нових технологій потребує значних зусиль, особливо коли мова йде про електронне навчання та засоби IКT, що його реалізують. У системі вищої медичної освіти цей процес характеризується підвищеною складністю. Проте, інформаційна революція значно вплинула та змінила напрями навчання у ВМНЗ. Новітні технології підвищили мотивацію та креативність викладачів, дали поштовх до самовдосконалення, роботи над подальшим створенням нових методів навчання.

3 метою полегшення процесу адаптації освітян до використання комп'ютерних засобів та ІКТ
Міжнародною асоціацією медичної освіти було розроблено "Методичні рекомендації з е-навчання в медичній освіті" (AMEE Guide to e-Learning in Medical Education), в яких розглянуто концепти “е-навчання", “е-викладання" та "е-оцінювання" $[4,455]$.

Навчання засобами IKT ефективне для засвоєння теоретичних знань і практичних умінь під час обгрунтування діагнозу, проте воно не може замінити методи огляду пацієнтів, що передбачають особисту присутність, і використовується лише для підготовки до цього виду діяльності. Клінічне обгрунтування вважається ключовою компетенцією майбутніх лікарів, для розвитку якої використовуються, переважно, традиційні методики навчання, форми лекцій, занять у невеликих групах студентів, а також медичної практики в Центрах симуляції. Однак, педагогічний підхід, основу якого складає навчання на реальних пацієнтах, стає щоразу менш доступним і прийнятним, особливо, якщо це стосується хірургічних втручань і випадків, пов'язаних із високим рівнем ризику. Це спонукає до пошуку альтернативних способів підготовки до професійних дій у подібних ситуаціях. Забезпечення виконання таких завдань у сучасній системі ВМО гарантують засоби електронного або Веб-доповненого навчання, віртуальна реальність і високоточні моделі-симуляції пацієнтів.

Зокрема, в медичній школі університету Флориди прийняте рішення, що кожна кафедра невідкладної допомоги має: 1) забезпечити доступ до навчальних матеріалів у Мережі та комп'ютеризованих тренувальних програм; 2) інтегрувати реальні автоматизовані засоби навчання в освітній процес; 3 ) заохотити педагогів до розвитку й оцінювання віртуальної реальності (BP); 4) забезпечити створення національнодоступних протоколів упровадження й оцінювання ВР і груп науковців для вивчення цього питання; 5) використовувати віртуальних пацієнтів під час навчання 3 метою оптимізації процесу підготовки майбутніх лікарів до фахової діяльності та комунікації. Такий новий підхід замінить застарілий принцип медичної освіти “одне бачить, одне робить, один вчить” (англ. see one, do one, and teach one), та реалізує новий принцип "одне бачить, багато разів відтворює, одне робить компетентно, всіх навчає" (англ. see one, simulate many, do one competently, and teach everyone).

3 метою втілення гібридної моделі навчання в комбіновані навчальні плани 3 використанням засобів е-навчання та традиційного навчання, що передбачає особистий контакт [5], у 2002 р. за 
участі п’ятдесяти провідних ВМНЗ США та Європи була створена Міжнародна віртуальна медична школа (IVIMEDS). IVIMEDS - це високоякісна ініціативна освітня партнерська програма. Дослідження учасників Програми орієнтовані на вивчення нового мислення та підходів щодо застосування інноваційних засобів навчання, в тому числі віртуальної реальності, а також нових підходів щодо організації навчальних планів, орієнтованих на потреби студентів, дослідження перспектив медичної освіти 3 урахуванням глобалізаційних процесів i, загалом, покращеної системи навчання, з використанням віртуальних пацієнтів.

Незворотній процес поширення цифрових технологій у системі вищої медичної освіти спричинив формування віртуальних “хмар" медичних знань та інформації, доступних студентам-медикам. Уже сьогодні студентами ВМНЗ є представники "цифрового покоління", які народилися після появи першого Інтернетбраузера (1993 р.). Безперечно, вони максимально використовуватимуть веб-інструменти в усіх видах професійної діяльності. Важливим завданням освітян $є$ використання засобів ІКТ для навчальних потреб, контролю й управління навчальним процесом.

Стрімка еволюція обчислювальної техніки і засобів зв'язку викликає необхідність прогнозування їх розвитку. Багатофункційні електронні пристрої на кшталт iPhone нині практично незамінні в повсякденному житті, на роботі та в навчанні. Майбутнім етапом розвитку технологій є розвиток “Інтернету Речей” (Internet of Things, IoT) та поширення переносних комп'ютерних пристроїв - “розумних аксесуарів" (wearable computers/wearables). ІоТ - це сукупність Інтернет-систем, упроваджених у сфери загального використання, що забезпечують взаємозв'язки продуктів використання та користувачів, які можуть здійснюватися автоматично, за допомогою машин - М2М (machine-to-machine), без участі людини. В експертному висновку ISO 2014 р. надано офіційне визначення ІоТ: “інфраструктура сполучених між собою об'єктів, людей, систем, інформаційних ресурсів та інтелектуальних сервісів, завдяки яким здійснюється оброблення інформації фізичного та віртуального світів та реакція на неї. Розумні аксесуари є прикладами перших засобів ІоТ. За прогнозами вчених, уже через вісім років вони стануть доступними більшості. Людина в Інтернеті - "homo nodus" зможе переносити декілька Інтернет-вузлів. Вплив таких технологій на навчальний процес буде значно суттєвішим, ніж списування під час екзаменів. Разом із можливостями реалізації групового та ситуативного навчання, використання мікро-камер може мати негативні наслідки, якщо не буде розроблено “антидот" технічні пристрої для їх виявлення у студентів.

Освітяни медичної галузі США традиційно приймають заходи щодо випередження неконтрольованого проникнення новітніх технологій у навчальне середовище та проводять випереджувальні дослідження цього майбутнього перспективного напряму, адже новітні технології мають потенціал позитивного впливу на освіту та навчання лише за умови зміни педагогічних технологій, а не лише їх використання для підтримання навчального процесу.

Висновки. Таким чином, характерними особливостями підготовки майбутніх лікарів у провідних університетах США $є$ унікальна структура медичної освіти і об'єднання процесів iii реформування та модернізації, що здійснюється за допомогою розвитку електронного навчання, в центрі якого - використання засобів IКТ із навчальною метою. Актуальними науковими тенденціями досліджень медичної освіти США $є$ використання можливостей віртуальної реальності за допомогою розумних аксесуарів.

\section{ЛITEPATУРA}

1. AMA Accelerating Change in Medical Education Consortium. [Elecronic resource]. Electronic data. Mode of access: https://www.ama-assn.org/ama/pub/aboutama/strategic-focus/accelerating-change-in-medicaleducation/schools.page. Title from the screen.

2. American Medical Association [Electronic resource]. [Internet-portal]. Electonic data. Mode of access: http://www.ama-assn.org/ama. - Title from the screen.

3. Cook, D., Levinson, A. \& Garside, S. (2008). Internet-Based Learning in Health Professionals: A Metaanalysis [Electronic resource]. pp. 1181-1196. Mode of access: http://jama.jamanetwork.com/article.aspx? articleid $=182536$. Title from the screen.

4. Ellaway, R. \& Masters, K. (2008). AMEE Guide 32: e-Learning in medical education Part 1: Learning, teaching and assessment [Electronic resource]. Med Teach. Electronic data. Vol. 30(5). P. 455-473. Mode of access: http:/www.tandfonline.com/doi/full/10.1080/ 01421590802108331. Title from the screen.

5. Manyuk, L. V. (2016). Computerization in Higher Medical Education of the USA and Ukraine. [Electronic resource]. Information technologies in education. No. 27 (27), pp. 222-232]. Mode of access: http:// ite.kspu.edu/Issue_27/p-222-232. Title from the screen.

6. NYU School of Medicine [Electronic resource]. Mode of access: http://www.med.nyu.edu/school/ education-training. Title from the screen.

7. Perelman School of Medicine. University of 


\section{СТАНОВЛЕННЯ НАЦІОНАЛЬНОЇ ІДЕНТИЧНОСТІ ТА ВИХОВАННЯ НАЦІОНАЛЬНО-СВІДОМОЇ ОСОБИСТОСТІ У ЗАХІДНІЙ УКРАЇНІ КІНЦЯ ХVІІІ СТ. - 1939 Р.}

Pennsylvania [Electronic resource]. Mode od access: http://www.med.upenn.edu/. - Title from the screen.

8. Ruiz, J. G., Mintzer, M. J. \& Leipzig, R. M. (2006). The impact of E-learning in medical education [Electronic resource]. Acad Med.Vol. 81(3), pp. 207-
212. Mode of access: http://www.ncbi.nlm.nih.gov/ pubmed/16501260. Title from the screen.

9. Stanford Medicine [Electronic resource]. Mode of access: http://med.stanford.edu/. Title from the screen

Стаття надійшла до редакції 26.02.2018

УДК 37.035.6:371(477.8) “ҮІІІ / XIX”

DOI:

Марія Багрій, кандидат філологічних наук, докторант ДВНЗ “Прикарпатський національний університет імені Василя Стефаника"

\section{СТАНОВЛЕННЯ НАЦІОНАЛЬНОЇ ІДЕНТИЧНОСТІ ТА ВИХОВАННЯ НАЦІОНАЛЬНО-СВІДОМОЇ ОСОБИСТОСТІ У ЗАХІДНІЙ УКРАЇНІ КІНЦЯ XVIII СТ. - 1939 Р.}

Стаття присвячена становленню начіональної ідентичності та вихованню начіонально-свідомоі особистості у Західній Украӥні кінця XVIII cm. - 1939 р. Здійснено порівняння концепту національної ідентичності в окремих регіонах, описано запропоновані шляхи відновлення національного коду, досліджено принциии виховання національно-свідомої особистості крізь призму етнічного та загальногромадянського змісту. Проаналізовано символічну складову та систему архетипів начіонального становлення Західної України означеної доби. Проаналізовано терміни “національна ідентичність” $i$ “національна ідея”, потрактовано національний компонент свідомості украйнців Західної України кіния XVIII cm. -1939 p.

Ключові слова: Київська Русь; начіональна ідентичність; начіональна ідея; начіонально-свідома особистість; Західна Україна; козаитво; опришківство.

תim. 15.

Mariya Bahriy, Ph.D.(Philology), Doctoral Student State Pedagogical University "Vasyl Stefanyk Precarpathian National University"

\section{DEVELOPMENT OFNATIONALIDENTITYANDEDUCATIONOFTHE NATIONAL- CONSCIOUS PERSONALITYIN WESTERNUKRAINE INTHE ENDOFTHE YEAR XVIII- 1939}

The article is devoted to the formation of national identity and the education of the national conscious personality in Western Ukraine at the end of the thirteenth century XVIII - 1939. The comparison of the concept "national identity" in certain regions is carried out, the proposed ways of restoration of the national code are described, and the principles of education of the national conscious person are explored through the prism of ethnic and general civic content. The symbolic component and a system of archetypes of the national formation of Western Ukraine of certain age have been analyzed. The terms "national identity" and "national idea" are analyzed, the national component of Ukrainian consciousness of Western Ukraine at the end of the thirteenth century is studied XVIII - 1939.

The period of each decay of nation is transformed into a national revival, which becomes possible because the nation did not manage to destroy it. The process of another uplift begins, in which the national consciousness at the ideological level has an exceptional significance. The national idea born on the wake of the national revival forms the national self-consciousness that can be considered both an indicator and a generator of the formation and development of a new nation, its transformation, a national idea that consolidates the nation, forming the core around which a national culture is created. Only that can be considered the national idea, national identity and national self-culture as the main components of the structure of the nation, as well as indicators of its birth and revival. It is necessary to begin to overcome the complex problems of education of youth, its national-patriotic education in its own, Ukrainian tradition, on its own samples of public, scientific victory in the name of the Ukrainian state.

The national idea should be based on a deep understanding of each Ukrainian about the Ukrainian national identity, identification with it, on forming perceptions about the typical features of the Ukrainian national community, its ethnic territory, language, historical and spiritual values.

Keywords: Kievan Rus; national identity; a national idea; the national conscious personality; Western Ukraine; Cossacks; Opryshchivstvo.

$\Pi$ остановка проблеми. Терміни “національна ідентичність" і “національна ідея” були на часі тоді, коли не існувало України як держави, але вони глибоко закорінились в історичні пласти людської свідомості. Полісемантичність терміна "нація", 